\title{
Erratum to: Informatics in Control, Automation and Robotics
}

\author{
Joaquim Filipe, Oleg Gusikhin, Kurosh Madani and Jurek Sasiadek
}

\section{Erratum to:}

\section{J. Filipe et al. (eds.), Informatics in Control, Automation} and Robotics, Lecture Notes in Electrical Engineering 370, DOI 10.1007/978-3-319-26453-0

The book was inadvertently published with incorrect subtitle in book frontmatter and cover. The correct subtitle of the book should read as "11th International Conference, ICINCO 2014 Vienna, Austria, September 2-4, 2014 Revised Selected Papers." The erratum book has been updated with the change.

The updated original online version for this book frontmatter can be found at 10.1007/978-3-319-26453-0

\footnotetext{
J. Filipe $(\triangle)$

INSTICC, Polytechnic Institute of Setúbal, Setúbal, Portugal e-mail: jfilipe@insticc.org

O. Gusikhin

Ford Research and Advanced Engineering, Dearborn, MI, USA

e-mail: ogusikhi@ford.com

K. Madani

University Paris-Est Créteil (UPEC), Créteil, France

e-mail: madani@u-pec.fr

J. Sasiadek

Mechanical and Aerospace Engineering, Carleton University, Ottawa, ON, Canada

e-mail: jurek_sasiadek@carleton.ca 